using Hirsch funnel with suction or ordinary funnel and filter paper with or without pressure; wash the precipitate by decantation twice with sixty per cent. nitric acid solution, using about fifty cc. of the solution each time, agitating thoroughly, and allowing the precipitate to completely settle, once with the same amount of three per cent. ammonium or potassium nitrate solution, ${ }^{1}$ transfer it to the filter, and wash it five or six times with water, using 150 to $250 \mathrm{cc}^{2}$ Now wash the filter and contents back into the beaker, add excess of standard alkali, and then a few drops of phenolphthalein, and titrate back with standard nitric acid.

\title{
THE ACTION OF NITRIC ACID UPON ALUMINUM AND THE FORMATION OF ALUMINUM NITRATE.
}

By Thomas B. Sitliman.

Received July 17, 8897 .

$\mathrm{T}$

$\mathrm{HE}$ bibliography of aluminum, in reference to the action of nitric acid upon the metal, is well worthy of investigation.

The statements are so conflicting, even in the recent literature bearing upon this subject, that direct experimentation was required to demonstrate the solubility of aluminum in nitric acid.

Wöhler" states: "Aluminium is not attacked by $\mathrm{HNO}_{3}+\mathrm{Aq}$ even when concentrated and boiling. ${ }^{4}$

Deville $^{5}$ gives as the result of his experiments that aluminum is not attacked by boiling nitric acid, dilute or concentrated.

Richards ${ }^{b}$ refers to the statement of Deville, but also adds: "In boiling acid solution takes place, but with such slowness that I had to give up this mode of dissolving the metal in my analysis." "By cooling the solution all action ceases."

Buff and Heeren" coincide with Deville, "Aluminium wird wedet von verd. noch konz. $\mathrm{HNO}_{3}$ angegriffen."

Montemartin," "Aluminium is slowly soluble in 27 per cent.

1 It is suggested that water be used for this washing by decantation instead of the nitrate solution.

2 In our experience $200 \mathrm{cc}$. of water is sufficient.

3 Pogg. Ann., 2, 223.

4 A Dictionary of Chemical Solubilities, by Comey, 3896 .

5 Compt. Rend., 38, 279.

B Aluminium, its Properties, Metallurgy and Alloys, by J. W. Richards, 1890 .

7 Handbuch der anorganische Chemie, Dammer, 2, 86, 1894 .

8 Gazz. Chim. Ital., 22, 397. 
$\mathrm{HNO}_{3}+\mathrm{Aq}$, , $100 \mathrm{cc}$. $\mathrm{HNO}_{3}+\mathrm{Aq}$, requiring 2 months to dissolve 2 grams of aluminium."

M. M. Pattison Muir" states, in relation to the chemical properties of aluminum: "It is scarcely attacked by $\mathrm{HNO}_{3}+\mathrm{Aq}$."

Weeren," "Aluminium is soluble in $\mathrm{HNO}_{3}+\mathrm{Aq}$ in zacuo."

Storer's Dictionary of Solubilities of Chemical substances, page 28 , gives the one reference only regarding the action of nitric acid upon aluminum, viz., " unacted upon by nitric acid, either concentrated or dilute, at ordinary temperatures, but is slowly dissolved therein on boiling."

N. Menschutkin, " Nitric acid has only a slight action upon aluminium, the layers of nitric oxide formed protecting the metal from further attack."

Ira Remsen:" At ordinary temperatures nitric and sulphuric acids do not act upon aluminium; at higher temperatures, however, action takes place."

Birnbaum, ${ }^{6}$ Concentrated and dilute nitric acid, either cold or warm, are without action upon aluminum. ("Concentrirte und verdiinnte Salpetersäure sind in der Kälte und Wärme ohne Wirkung auf Aluminium." )

W. Borchers," Nitric acid is almost without action upon aluminum. ("Salpetersäure ist fast ganz unwirksam auf Aluminium." )

Ferdinand Fischer," "Nitric acid and sulphuric acid scarcely affects aluminium."

J. Arthur Phillips, "Aluminium is not attacked by cold nitric acid, and only slowly on boiling."

Ad. Wurtz," "Nitric acid, dilute or concentrated, has no effect upon aluminium at ordinary temperatures. On boiling, however, solution of the metal is effected with extreme slowness."

1 A Dictiouary of Chemical Solubilities, by Comey, 3

2 Watt's Dictionary of Chemistry, 1, I42. (latest edition).

3 Ber. d. chem. Ges., 24, 7798.

4 Analytical Chemistry, by N. Menschutkin, London, 1895, p. 64.

5 Inorganic Chemistry, by Ita Remsen, N. Y., 1895, p. 452.

6 Handworterbuch der Chemie, Fehling, I, 339.

I L,exicon der gesamten Technik, Leuger, Leipzig, 1896, r, 262.

8 Manual of Chemical Technology, (Wagner), i3th German edition as remodelled by Dr. Ferdinand Fischer, p. 223.

9 Elements of Metallurgy, by J. Arthur Phillips and H. Bauermaun, 528

19 Dictionnaire de Chemie, $I, I 67$. 
Alfred E. Hunt, John W. Langley, Charles M. Hall," "Aluminium is unaffected by either concentrated sulphuric or nitric acids."

Encyclopedia Britannica, 1, 647, states: "Aluminium is not attacked by nitric acid, even when the acid is concentrated,"

Charles M. Hall," "Sulphuric and nitric acids act upon aluminium with extreme slowness, not dissolving it appreciably after several days' exposure to their action."

Henry Roscoe, "Sulphuric and nitric acids, both dilute and concentrated, have no effect upon aluminium."

Hanford Henderson," "Aluminium is almost untouched by nitric and sulphuric acids."

G. A. Leroy," Sulphuric and nitric acids act immediately upon aluminium. "(Schwefelsäure und salpetersäure griefen das aluminium schnell an.")

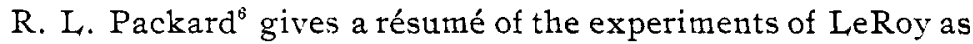
follows: "LeRoy used aluminium foil having the composition of 98.28 per cent. to 99.60 per cent. aluminium; 1.60 per cent. to 0.30 per cent. iron; 0.25 per cent. to 0. Io per cent. silicon.

The foil was polished, freed from fat with caustic soda, washed with alcohol, dried in the air-bath, cut up, weighed and introduced into the acids.

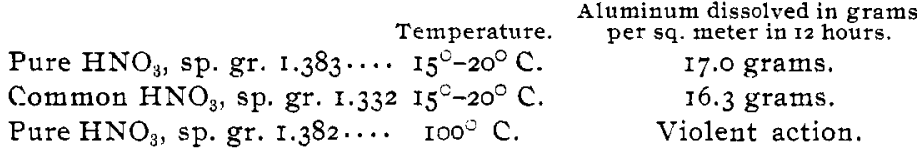

According to these results, almost pure aluminum, 99.5 per cent, is attacked even in the cold by nitric acid.

Very elaborate experiments were made by G. Lunge and E. Schmid' regarding the action of nitric acid upon aluminum. They show that aluminum is readily attacked by nitric acid of I.20 sp. gr. at ordinary temperatures, and that with nitric acid of sp. gr. I.50 the action is comparatively feeble.

\footnotetext{
1 The Properties of Aluminium, wih Some Information Relating to the Metal. Trans. Amer. Mining Engineers, $28,537$.

2 The Properties of Aluminium. Electrical World, $17,390$.

8 Aluminium. Nature, 40,185 .

4 Aluminium. J. Frank, Inst., 126, 293.

5 Action of Sulphuric and Nitric Acids upon Aluminium. Chem. Ztg, Repert, 15, 276; Bull. Rouen, I9, 232.

6 Bull, U. S. Geological Survey, 1893; This Journal, I5, 221.

iZtschr. angew. Chem., 1892, 7.
} 
The following table shows the results of the action of various strengths of nitric acid upon aluminum foil at ordinary temperature $\left(20^{\circ} \mathrm{C}\right.$. $)$; duration of test being ten days.
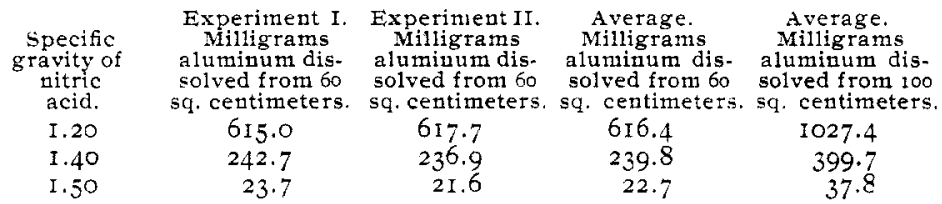

These experiments were conducted in the chemical laboratory of the Zurich "Polytechnicum."

The aluminum was in the form of sheet metal, cut into strips of eighty $\mathrm{mm}$. long, twenty-seven $\mathrm{mm}$, wide, and one $\mathrm{mm}$. thick. Its composition was: Aluminum 99.2 per cent., iron 0.25 per cent., combined silicon 0.44 per cent., and crystallized silicon o. I per cent.

Messrs. Lunge and Schmid conclude as follows:

"Several experiments made by us convince us that the statements in the text-books, according to which aluminum is slightly or not at all attacked by $\mathrm{HNO}_{3}$, are decidedly incorrect; which fact brings to naught the hope entertained that this metal can be used in the manufacture of nitric acid.'

In confirmation of these tests I made the following experiments, using aluminum (manufactured by the Pittsburg Reduction Co.) containing 99.6 per cent. of aluminum.

Coarse turnings were made of the metal, and six samples, each of one gram, were transferred to glass flasks and treated as follows :

\section{EXPERIMENT I.}

Specific gravity of nitric acid............ I.I5

Amount of acid taken.$\ldots \ldots \ldots \ldots \ldots \ldots \ldots$ roo $\mathrm{cc}$.

Length of test $\ldots \ldots \ldots \ldots \ldots \ldots \ldots \ldots \ldots \ldots, 7$ days

Temperature of acid.................. $20^{\circ} \mathrm{C}$.

Per cent. of aluminum dissolved........... 94.2

I. Result $=94.2$ per cent. aluminum dissolved.

EXPERIMENT II.

Specific gravity of nitric acid ............ I.I5

Amount of acid taken................. Ioo cc.

Length of test $\ldots \ldots \ldots \ldots \ldots \ldots \ldots \ldots \ldots \ldots \ldots, \quad 20$ minutes

Temperature of acid..$\ldots \ldots \ldots \ldots \ldots \ldots \ldots$ Io $\mathrm{C}$.

Per cent. of aluminum dissolved............ Ioo

II. Result $=100$ per cent. aluminum dissolved. 
EXPERIMENT III.

Specific gravity of nitric acid ........... I.35

Amount of acid taken................. I00 cc.

Length of test $\ldots \ldots \ldots \ldots \ldots \ldots \ldots \ldots \ldots \ldots, 7$ days

Temperature of acid $\ldots \ldots \ldots \ldots \ldots \ldots \ldots \ldots, 20^{\circ} \mathrm{C}$.

Per cent. of aluminum dissolved .......... 89

III. Result $=89$ per cent. aluminum dissolved.

EXPERIMENT IV.

Specific gravity of nitric acjd ............ I.35

Amount of acid taken................. I00 cc.

Length of test $\ldots \ldots \ldots \ldots \ldots \ldots \ldots \ldots \ldots \ldots \ldots$, 30 minutes

Temperature of acid $\ldots \ldots \ldots \ldots \ldots \ldots \ldots \ldots$ I00 ${ }^{\circ} \mathrm{C}$.

Per cent. of aluminum dissolved.......... I00

IV. Result $=$ Ioo per cent. aluminum dissolved.

EXPERIMENT V.

Specific gravity of nitric acid ........... I. 46

Amount of acid taken ................. I00 cc.

Length of test $\ldots \ldots \ldots \ldots \ldots \ldots \ldots \ldots \ldots \ldots \ldots . \quad 7$ days

Temperature of acid $\ldots \ldots \ldots \ldots \ldots \ldots \ldots \ldots .20^{\circ} \mathrm{C}$.

Per cent. of aluminum dissolved............ Ioo

V. Result $=$ I2 per cent. aluminum dissolved. EXPERIMENT VI.

Specific gravity of nitric acid ............ I. 46

Amount of acid taken................. $200 \mathrm{cc}$.

Length of test $\ldots \ldots \ldots \ldots \ldots \ldots \ldots \ldots \ldots \ldots \ldots, 2$ hours

Temperature of acid $\ldots \ldots \ldots \ldots \ldots \ldots \ldots \ldots$ I00 ${ }^{1)} \mathrm{C}$.

Per cent. of aluminum dissolved ........... Ioo

VI. Result $=$ complete solution.

These results show that aluminum in the form of coarse turnings is readily acted upon by nitric acid, hot or cold, the solution of the metal being more rapid in nitric acid, of sp. gr. I.15, than with the stronger acid of sp. gr. 1.45. In this connection, no doubt, the form in which the metal exists has a material influence upon the rapidity of solution in nitric acid.

If the metal be in thick plates the action of the nitric acid is very much retarded.

$\mathrm{N}$. Menschutkin ${ }^{1}$ considers that a layer of nitric oxide is formed, protecting the metal from further action of the acid.

To prove or disprove this statement, I selected a piece of aluminum (of the same composition as that with which the above experiments were made), one inch long, one inch wide,

1 Analytical Chemistry, by N. Menschutkin, London, 1895, p. 65 . 
and one-half inch thick. This was placed in a large flask, 700 cc. of nitric acid, I.35 sp. gr., added and kept at a temperature of $100^{\circ} \mathrm{C}$., for five hours, when complete solution of the aluminum was effected. The result of these tests shows that while aluminum in thin foil, or coarse turnings, is easily dissolved in nitric acid, hot or cold, solution is materially retarded in hot nitric acid if the aluminum be present in thick plates, and that solution in cold nitric acid is practically nil under the same contditions.

The solution of aluminum nitrate which I obtained from experiment IV deposited crystals of aluminum nitrate in the form of colorless, truncated, rhombic, octahedral crystals, similar in composition to those described by Ordway, ${ }^{1}$ of the composition

$$
\mathrm{Al}_{2}\left(\mathrm{NO}_{3}\right)_{6}+\mathrm{I}_{8} 8 \mathrm{H}_{2} \mathrm{O} \text {. }
$$

Ordway, however, obtained the aluminum nitrate by dissolving recently precipitated aluminum hydroxide in nitric acid and slowly concentrating, the crystals having the form of colorless rhombic prisms.

A. Ditte ${ }^{2}$ describes a basic aluminum nitrate, obtained by the action of dilute nitric acid upon aluminum, of the composition $\mathrm{Al}_{3}\left(\mathrm{NO}_{3}\right)_{2}+{ }_{4} \mathrm{H}_{2} \mathrm{O}$. It exists as a white precipitate in the form of fine needles. ${ }^{3}$

I have failed to find in the bibliography of aluminum nitrate any reference to the formation of $\mathrm{Al}_{2}\left(\mathrm{NO}_{3}\right)_{6}+{ }_{1} 8 \mathrm{H}_{2} \mathrm{O}$ by the direct action of nitric acid upon aluminum, as obtained in experiment IV, above described.

DEPARTMENT OF ANALYTICAL CHEMISTRY, STEVENS INSTITUTE OF TECHNOLOGY.

I Am.J. Sci. (2), 9, 33 .

2 Compt, rend., I10, 782 .

3 Handbuch der anorganische Chemie, Dammer, 3, 106. 